\title{
Different Circulating Ghrelin Responses to Isoglucidic Snack Food in Healthy Individuals
}

Authors

Affiliations

\author{
S. Benedini ${ }^{1}$, R. Codella ${ }^{1}$, A. Caumo ${ }^{2}$, F. Marangoni ${ }^{3}$, L. Luzi ${ }^{1,2}$
}

${ }^{1}$ Department of Sport, Nutrition and Health Sciences, University of Milan, Milan, Italy ${ }^{2}$ Internal Medicine, Section of Nutrition/Metabolism, H San Raffaele Scientific Institute, Milan, Italy ${ }^{3}$ Nutrition Foundation of Italy (NFI), Milan, Italy
Key words

- ghrelin

- snack food

- OGTT received 23.07 .2010 accepted 22.11.2010

\section{Bibliography}

DOI http://dx.doi.org/

10.1055/s-0030-1269900

Published online:

January 10, 2011

Horm Metab Res 2011;

43: $135-140$

(c) Georg Thieme Verlag KG

Stuttgart · New York

ISSN 0018-5043

Correspondence

\section{Luzi, MD}

University of Milan

Faculty of Exercise Sciences

4/A Kramer

20129 Milan

Italy

Tel.: + 39/02/503 15154

Fax: + 39/02/503 15152

livio.luzi@unimi.it

\section{Abstract}

$\nabla$

The last decade has seen much debate on ghrelin as a potential target for treating obesity. Despite a close connection between snack food intake and obesity, snacking is controversially reviewed as a good habit in a healthy nutritional regimen. The aim of the study was to evaluate whether a different nutrient composition influences postprandial ghrelin levels and glucose increments induced by 6 isoglucidic snack food. 20 healthy individuals $(10 \mathrm{M} / 10 \mathrm{~F}$; BMI $23.1 \pm 0.5$; age $33 \pm 0.67$ years, mean and SE) from $H$ San Raffaele Scientific Institute and Milan University were enrolled. The subjects underwent OGTT (50g) and 6 isoglucidic test-meal loads to assess the ghrelin circulating levels and the area under glycemic curves induced by 6 commercial snacks.

\section{Abbreviations \\ $\nabla$ \\ OGTT oral glucose tolerance test \\ HDL high density lipoproteins \\ LDL low density lipoproteins \\ TG triglycerides \\ FFAs free fatty acids}

\section{Introduction \\ $\nabla$}

It is still debated whether the use of snack-food throughout the day could be included in a healthy nutritional regimen [1]. Although Western societies exceed in over-intake of any sort of food, resulting in a constant rise in obesity and type 2 diabetes [2,3], the deleterious effects of snacks on increased hunger are still under examination [2]. The negative connotation of snack food usually arises from the notion of excess of calories accompanied by low nutritional values, therefore leading to an unbalanced energy intake with serious consequences especially among adoles-
$3 \mathrm{~h}$ after hazelnut chocolate intake, ghrelin was significantly lower than with wafer chocolate intake ( $p<0.002$ ). As a response to all snacks, the glycemic curves were not different even though hazelnut chocolate showed the lowest glycemic curve. Moreover, snack fat content was found to be inversely correlated to 3-h plasma ghrelin levels $\left(\mathrm{p}<0.0001 ; \mathrm{R}^{2}=0.77\right)$ and positively associated with satiety scores $\left(\mathrm{p}<0.02 ; \mathrm{R}^{2}=0.28\right)$. Also energy load was inversely correlated to $3-\mathrm{h}$ plasma ghrelin $\left(\mathrm{p}<0.0001 ; \mathrm{R}^{2}=0.73\right)$. Our results indicate that snack food administered in equivalent glucidic loads elicits postprandial ghrelin suppression and satiety ratings in different ways. Further studies are needed to elucidate the role of ghrelin as hunger-hormone in the regulation of energy balance. 
diet-induced obesity by modulating lipid metabolism [14]. According to the International Obesity Task Force [15], there is a low correlation, if any, between confectionery and obesity, indicating only a marginal role played by confectionery in daily caloric intake across Europe [16]. While in the last 2 decades much discussion had arisen about the effects of high energy meals or diets on metabolism and health, the specific metabolic mediators of these effects are still poorly understood $[17,18]$. Among the metabolic responses determined by food, some hormone profiles reveal interesting information on energy balance regulation. Ghrelin, for instance, is an orexigenic hormone primarily synthesized by the enteroendocrine cells of the stomach [19] and it seems to be involved, along with leptin, in the management of the metabolic balance $[20,21]$. It is a 28 -amino residue peptide engaged in a wide spectrum of pleiotropic actions, consistent with broad distribution of ghrelin receptors in central and peripheral tissues. Circulating ghrelin levels are negatively associated with food intake, glucose, insulin, and somatostatin, whereas ghrelin levels are increased by fasting and energy restriction [22-26]. Indeed, human studies have found a preprandial rise and postprandial decline in plasma ghrelin levels of putative gastric origins, suggesting an implication in energy homeostasis $[23,27]$. In other words, ghrelin could promote weight gain and adiposity through its metabolic actions: increasing appetite on the one side, and decreasing energy expenditure and fat catabolism on the other [28]. As a metabolic mediator, ghrelin might therefore be considered as an important biomarker of food-response and satiety.

To investigate the glycemic and hormonal responses elicited by 6 common commercial snacks, normal young volunteers undergoing glucose oral- and isoglucidic test-meal loads were studied. The impact of snack food with an equal amount of carbohydrates on postprandial ghrelin suppression was evaluated.

\section{Subjects and Methods \\ $\nabla$}

\section{Selection criteria}

20 healthy volunteers ( 10 men/10 women, age $18-40$ years) on a stable diet, with normal glucose tolerance and no dyslipidemia (according to ADA and ATPIII-NCEP guidelines, respectively) were recruited for this study ( $\bullet$ Table 1 ).

The ethical approval was obtained from the Ethical Committee at San Raffaele Scientific Institute. All subjects signed up for a written informed consent prior to participation, according to the Declaration of Helsinki. All the procedures used complied with the Good Clinical Practice (GCP) principles. A medical history and a $75 \mathrm{~g}$ oral glucose tolerance test (OGTT) were performed to determine eligibility for participation.

\section{Study protocol}

This randomized study was carried out at the Nutrition and Metabolism Unit of San Raffaele Scientific Institute (Milan, Italy). After overnight fasting, the subjects were admitted to hospital at 08:30-09:00; they rested in a supine position for about $10 \mathrm{~min}$. After that, an indwelling catheter was inserted in an antecubital arm vein. During the preliminary examination, 20 subjects drank an aqueous solution of $75 \mathrm{~g}$ of glucose to determine plasma glucose (OGTT) and basal lipid profile (HDL, LDL, TG, FFAs). If the results matched the inclusion criteria, in the subsequent sessions the volunteers were to take a $50 \mathrm{~g}$ glucose load or a corresponding carbohydrate portion of 6 snack-meals. Each meal was eaten in a
Table 1 Anthropometrical and clinical characteristics of the study subjects

\begin{tabular}{|lc} 
& Mean \pm SE \\
\hline Sex $(\mathrm{M} / \mathrm{F})$ & $10 \mathrm{M} / 10 \mathrm{~F}$ \\
Age (years) & $33 \pm 0.67$ \\
\hline Weight $(\mathrm{kg})$ & $68.9 \pm 3.3$ \\
Height $(\mathrm{cm})$ & $1.71 \pm 0.01$ \\
\hline BMI $\left(\mathrm{kg} / \mathrm{m}^{2}\right)$ & $23.1 \pm 0.5$ \\
\hline Fasting glucose $(\mathrm{mmol} / \mathrm{l})$ & $4.43 \pm 0.07$ \\
\hline 2-H glucose $(\mathrm{mmol} / \mathrm{l})$ & $4.28 \pm 0.25$ \\
\hline
\end{tabular}

Table 2 Energy load and macronutrient composition per $50 \mathrm{~g}$ carbohydrate snack meal

\begin{tabular}{lccc}
\hline Snack & Energy (kcal) & Fat (g) & Protein (g) \\
\hline B: hazelnut cream filled chocolate & 604 & 40.4 & 9 \\
\hline C: milk chocolate & 526 & 32 & 9.4 \\
\hline D: cream milk filled sponge cake 1 & 469 & 24.6 & 11.9 \\
\hline E: wafer chocolate & 406 & 20.4 & 5.3 \\
\hline F: cream milk filled sponge cake 2 & 461 & 25 & 8.8 \\
G: cream milk filled cake (chilled) & 588 & 37.7 & 12.3 \\
\hline The subjects consumed each portion on different test days. Percent nutrient values \\
not counted above are derived from the amounts of fibres, vitamins, and minerals \\
(traces) plus water
\end{tabular}

randomized order on separate days $\sim 2$ weeks apart, to ascertain lipidemia, plasma glucose, and plasma hormone profile.

\section{Blood samples}

After fasting, blood samples were obtained $\left(0^{\prime}\right)$. The subjects received either a test meal or $50 \mathrm{~g}$ glucose. Hence, additional blood samples were taken at $15,30,45,60,75,90,120,180 \mathrm{~min}$ after the meal.

\section{Snack food meals}

All snacks ( $\odot$ Table 2 ) were administered at $\sim 09: 00 \mathrm{~h}$ and eaten for breakfast within $10 \mathrm{~min}$.

\section{Analytical methods}

The total amount of blood drawn for each test was about $22.5 \mathrm{ml}$ for each participant. All blood samples were placed on ice until plasma or serum was separated by centrifugation at $4^{\circ} \mathrm{C}$ (within $1.5 \mathrm{~h}$ from sampling). All plasma and serum aliquots were frozen at $-60^{\circ} \mathrm{C}$ for later analysis. All the samples were measured in duplicate. Plasma glucose was measured at the bedside with a glucose analyzer (Beckman Instruments, Fullerton, CA, USA). Aliquots of blood for measurement of ghrelin were collected in test tubes containing EDTA; all the samples were kept in ice and the plasma prepared by centrifugation at $4{ }^{\circ} \mathrm{C}$ within $1.5 \mathrm{~h}$ from sampling. The ghrelin level was measured through the enzyme immunoassay method (LINCO Research Inc., St. Charles, MO, USA). Free-insulin was dosed by a highly specific 2-site monoclonal antibody-based immunosorbent assay (ELISA; Dako Diagnostics, Cambridgeshire, UK). The lipid profile and FFA were measured through the immunoenzymatic technique [29].

\section{Satiety}

A $100 \mathrm{~mm}$ linear visual analogue scale (VAS) was used to assess the volunteers' subjective feelings of satiety [30]. Subjects were instructed to rate both their fullness and hunger at $0,30,60,90$, 120 , and $180 \mathrm{~min}$ from the meal assumption by making a single vertical mark on a scale ranging from the most negative to the most positive score (e.g., from "not hungry" to "hungry"). The 

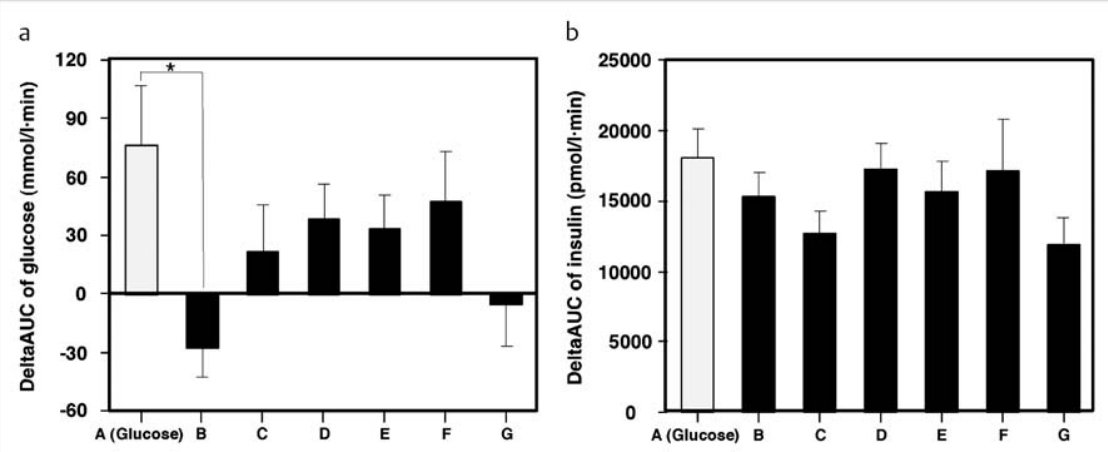

Fig. 1 a: Glucose $\triangle$-AUC (mmol/l- min) induced by $50 \mathrm{~g}$ glucose load (white bar $\mathrm{A}$ ) and $50 \mathrm{~g}$ carbohydrate snack meal loads (black bars B, C, D, E, F, G). b: insulin $\triangle$-AUC (pmol/l- min) induced by $50 \mathrm{~g}$ glucose load (white bar A) and $50 \mathrm{~g}$ carbohydrate snack meal loads (black bars B, C, D, E, F, G). The equality of the means of glucose and insulin $\triangle$-AUC (continuous variables) in the 6 snacks and glucose load were tested using repeated measures ANOVA followed by the Newman-Keuls test for multiple pairwise comparisons. ${ }^{*} p<0.05$.

satiety scores were then plotted against time for each experiment.

\section{Statistical analysis}

The incremental area under the glucose and insulin concentration curves, the 3-h plasma ghrelin concentration, and the 3-h satiety score were used as summary measures of the metabolic responses resulting from the intake of either glucose or one of the 6 snacks. The incremental area under the curve $(\triangle$-AUC) was calculated as the difference between the total area under the curve and the product of the basal, pretest concentration time during the experiment (i.e., $180 \mathrm{~min}$ ). The equality of the means for the increment of glucose and insulin concentration, and for the 3-h plasma ghrelin concentration (continuous variables) in the 6 snacks (glucose was not considered) were tested using repeated measures ANOVA followed by the Newman-Keuls test for multiple pairwise comparisons (an $\alpha$ level of 0.05 was chosen). In order to assess possible evidence of a difference in the 3-h satiety score (an ordinal variable) among the 6 snacks, Friedman's rank test was performed followed by Dunn's test for multiple pairwise comparisons (an $\alpha$ level of 0.05 was chosen).

The study of the relationships between the fat content of the snacks and the 3-h satiety score, the caloric load of the snacks and the 3-h satiety score, as well as the fat content of the snacks and the 3-h plasma ghrelin concentration entailed the analysis of repeated observations from several subjects and could not be performed through simple regression. These data were analyzed using multiple regression as suggested in Bland et al. [31]. The analysis consisted in fitting parallel lines through each subject's data. The common regression slope was reported together with the correlation coefficient (obtained from the squared root of the coefficient of determination provided by the multiple regression) and with the p-value obtained from the F-test in the associated ANOVA table.

\section{Results \\ $\nabla$}

\section{Subjects}

The demographic data are summarized in $\bullet$ Table 1 . All subjects (10 males and 10 females) were healthy and lean (body mass index $23.1 \pm 0.5 \mathrm{~kg} / \mathrm{m}^{2}$ ), and had a normal response to the oral glucose tolerance test. The subjects reported no differences in activity levels prior to each test day.

\section{Plasma glucose}

Fasting plasma glucose was similar and within the normal range in all subjects $(4.43 \pm 0.07 \mathrm{mmol} / \mathrm{l})$. During the $50 \mathrm{~g}$ OGTT (A), plasma glucose level peaked at $60 \mathrm{~min}(5.69 \pm 0.32 \mathrm{mmol} / \mathrm{l} \mathrm{vs}$. baseline; $\mathrm{p}<0.0002$ ) and dropped significantly below the baseline after $3 \mathrm{~h}(3.96 \pm 0.21 \mathrm{mmol} / \mathrm{l}$ vs. baseline; $\mathrm{p}<0.01)$. After snack B intake, plasma glucose concentration at $60 \mathrm{~min}$ was slightly lower than the basal condition $(4.27 \pm 0.19 \mathrm{mmol} / \mathrm{l} \mathrm{vs}$. baseline $4.6 \pm 0.1 \mathrm{mmol} / \mathrm{l}, \mathrm{p}<0.05)$. However, baseline was progressively restored at $180 \mathrm{~min}(4.52 \pm 0.1 \mathrm{mmol} / \mathrm{l}$ vs. baseline $4.6 \pm 0.1 \mathrm{mmol} / \mathrm{l})$. The glucose peak was not statistically different in all snack meal, only during OGTT the peak was higher than all other meals $(p<0.01)$.

\section{Areas under glycemic curves (AUC_glu)}

The areas under the curve (AUC) were calculated from 0 to $180 \mathrm{~min}$ for glucose. The areas under the glycemic curves were disparate for all snacks. In particular, the $\Delta$-AUC_glu of snack B was definitively lower than the one obtained during the OGTT $(p<0.05)$, whereas other incremental curve's values were not significantly different ( $\bullet$ Fig. 1a).

\section{Plasma Insulin and Areas under the insulinemic curves (AUC_ins)}

The basal plasma insulin was similar in all subjects $(36.46 \pm 4.01 \mathrm{pmol} / \mathrm{l})$. After ingestion of all snacks, the insulin levels peaked significantly at $60 \mathrm{~min}$ from the mean basal condition $(p<0.001)$. The insulin peak of snack $G$ was lower with respect respect to snacks $D$ and $F(p<0.05$ and $p<0.03$, respectively). The delta areas under the insulin curves ( $\triangle$-AUC_ins) after ingestion of snack $\mathrm{G}$ showed a trend to be lower than those of snack $\mathrm{D}(\mathrm{p}=0.07)$ and $\mathrm{F}(\mathrm{p}=0.08)$ ( $\bullet$ Fig. 1b).

\section{Ghrelin}

Plasma ghrelin was within the normal range in the basal condition $(248.5 \pm 5.2 \mathrm{pg} / \mathrm{ml})$ in all subjects after an overnight fast (about $12 \mathrm{~h}$ ). As a response to snack B, the final ghrelin was significantly lower with respect to the final value recorded after the assumption of snack E $(\mathrm{p}<0.01)$ ( $\bullet$ Fig. $2 \mathrm{a})$. The postprandial ghrelin suppression was proportional to the energy load of the snack food $\left(\mathrm{p}<0.0001 ; \mathrm{R}^{2}=0.73\right.$; energy load slope coefficient $=-0.158$ ) since 3 -h plasma ghrelin levels were negatively correlated to snack fat content $\left(\mathrm{p}<0.0001 ; \mathrm{R}^{2}=0.77\right.$; fat slope coefficient $=-2.114)(\diamond$ Fig. 3 )

\section{Satiety}

All snacks (B, C, D, E, F, and G) showed a satiety score higher than glucose load (all snacks vs. glucose; p<0.05) $180 \mathrm{~min}$ after assumption. Snacks B, D and G showed the highest final satiety ratings. In particular, the final score recorded after snack $G$ intake was higher than those reported after $\mathrm{C}, \mathrm{E}$ and $\mathrm{F}$ ingestion $(p<0.001)$, whereas the 3 -h satiety scores of B and D were higher than those of $\mathrm{C}$ and $\mathrm{F}$ ( $\bullet$ Fig. 2b). The final satiety scores were 


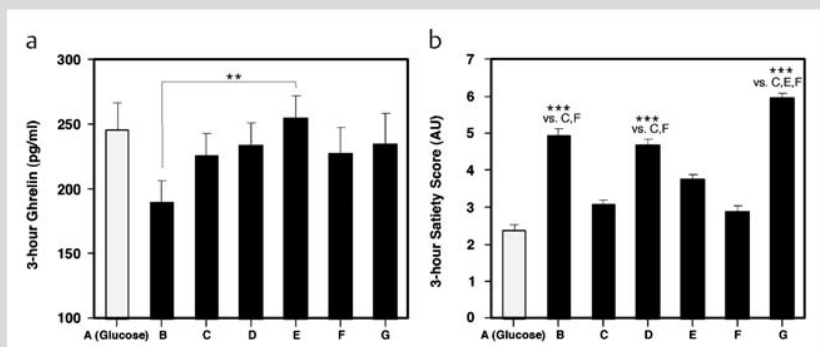

Fig. 2 a: 3-h ghrelin (pg/ml) induced by $50 \mathrm{~g}$ glucose load (white bar A) and $50 \mathrm{~g}$ carbohydrate snack meal loads (black bars B, C, D, E, F, G). Panel b: final satiety score (AU: Arbitrary Unit) $180^{\prime}$ after glucose assumption or all other snacks. The equality of the means of 3-h plasma ghrelin concentration (continuous variables) in the 6 snacks (glucose was not considered) were tested using repeated measures ANOVA followed by the Newman-Keuls test for multiple pairwise comparisons. To assess whether there was evidence of a difference in the 3-h satiety score (an ordinal variable) among the 6 snacks, Friedman's rank test was performed followed by Dunn's test for multiple pairwise comparisons. ${ }^{* *} \mathrm{p}<0.01$; ${ }^{* * *} \mathrm{p}<0.001$.

positively correlated to the fat content of the snacks $(\mathrm{p}<0.02$; $\mathrm{R}^{2}=0.28$; fat slope coefficient $\left.=0.085\right)(\odot$ Fig. 3 ).

\section{Discussion}

$\nabla$

This study found some variations in the ghrelin hormonal responses of healthy individuals after consumption of 6 different snacks. Under isoglucidic conditions, the nutritional composition of the snack food appeared to be determinant in eliciting changes in the hormonal profiles. While there is evidence that the total ghrelin level is an indicator of appetite in humans, the effect of nutrient composition on its postprandial response is less clear. Diet nutrient composition does affect circulating ghrelin levels, as it has been reported many times [32], but the extent to which postprandial ghrelin suppression occurs relative to distinct macronutrients is not univocal. Previous experiments were conducted with carbohydrate-rich test meals as high carbohydrate ingestion seems to exert stronger ghrelin-suppressing signals than other macronutrients. Moreover, a linear relationship between ghrelin decrease and carbohydrate content of a meal has been already recognized. In the current study, snack food with and equal amount of carbohydrates was administered in order to test whether other nutrients could predominantly mediate the circulating ghrelin postprandial fall.

It has already been shown that fat and protein influence glucose and insulin responses $[33,34]$, although other works have observed no relationship between postprandial ghrelin and plasma glucose or insulin $[35,36]$. In those studies the lack of uniformity cast doubts on whether a specific nutritional factor of the meal rather than its induced metabolic response influenced postprandial ghrelin suppression.

Here, the glucose $\Delta$-AUCs produced by all snacks were not significantly different, whereas those induced by $50 \mathrm{~g}$ OGTT were the highest.

Interestingly, the fat content inversely correlated with the plasma ghrelin levels reached $3 \mathrm{~h}$ after the ingestion of half of the snack food. Snack food B had a considerable amount of fat (37.5/100 g of product, - Table 2 ), possessed a high satiety score, and showed the lowest final ghrelin levels.
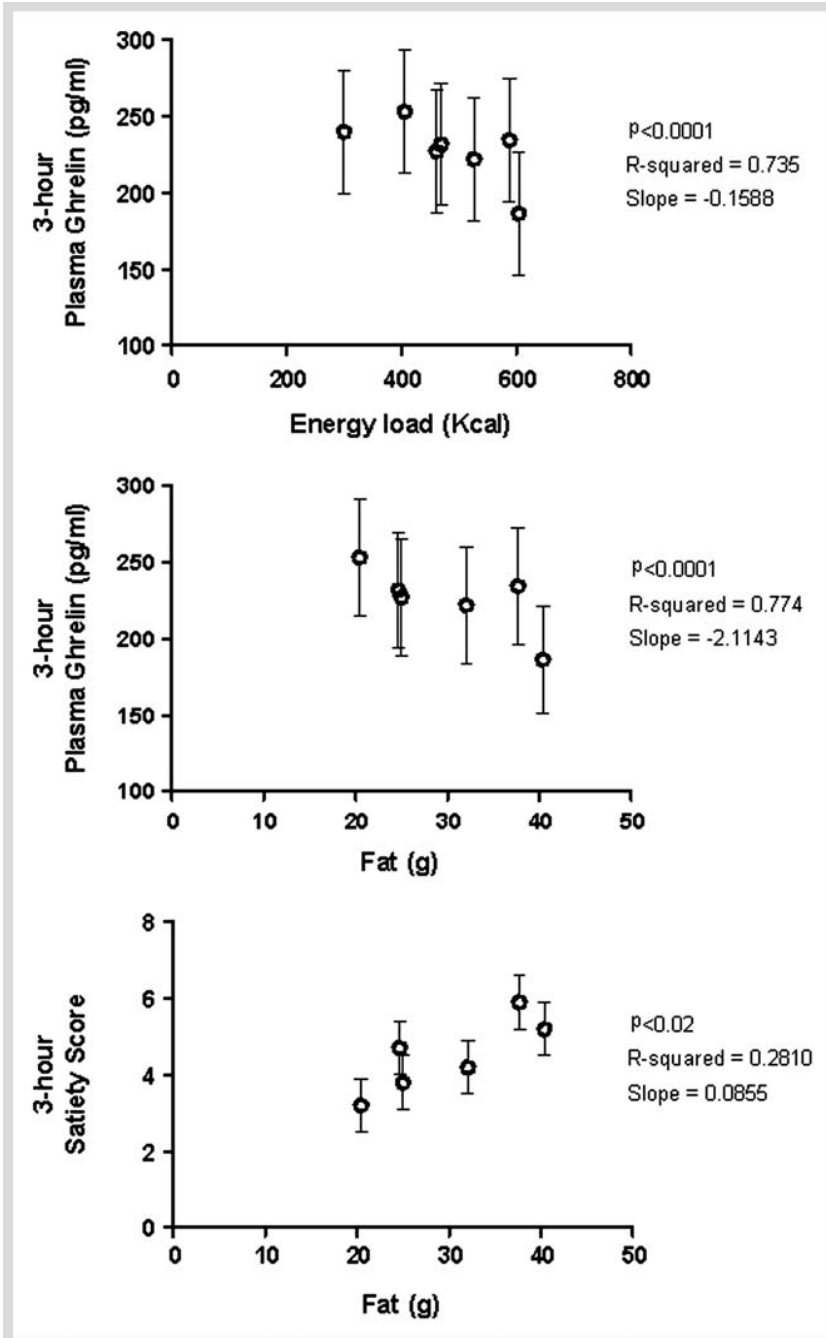

Fig. 3 Upper panel: inverse correlation between 3-h plasma ghrelin levels and energy load $(\mathrm{kcal})\left(p<0.0001 ; R^{2}=0.73\right)$. Middle panel: negative correlation between 3-h plasma ghrelin levels and fat $(p<0.0001$; $\left.R^{2}=0.77\right)$. Lower panel: positive association between fat content and satiety scores $\left(p<0.02 ; R^{2}=0.28\right)$. The relationship between the fat content of the snacks and the 3-h satiety score, the energy load of the snacks and the 3-h satiety score, as well as the fat content of the snacks and the 3-h plasma ghrelin concentration entailed the analysis of repeated observations from several subjects and could not be performed through simple regression. The common regression slope was reported together with the correlation coefficient (obtained from the squared root of the coefficient of determination provided by the multiple regression) and with the $\mathrm{p}$-value obtained from the F-test in the associated ANOVA table.

Hunger and satiety ratings were not substantially different among all snacks besides B, D, and G - those with a high fat content and also the most satisfying ones throughout the 3-h experiment. As a corollary to this, satiety scores were found to be associated with fat content, implying a satiating-effect of lipids in these snacks besides carbohydrates. Thus, unlike recent studies [37], fat content rose as an important marker of satiety. This was not the sole variable determining ghrelin responses, which possibly resulted from a combination of different nutrient contributions, instead.

Likewise, the depth of postprandial ghrelin decline was related, in a dose-dependent manner, to the amount of fat in a snack food, when other major ghrelin-suppressing macronutrients, that is, carbohydrates were held constant. 
As already ascertained elsewhere, the postprandial ghrelin decline was found proportional to the consumed calories: a robust inverse relationship was in fact observed between absolute plasma ghrelin levels and the caloric content of the meal. Given this, the energy density of the snack remains an issue for food industries committed in sorting out a healthy dietary regimen combined with a hedonistic lifestyle. As already stressed by many policy makers' recommendations to limit the intake of excessive free calories, energy dense snacks should be carefully considered when looking for palatal pleasure.

These findings confirm the involvement of ghrelin in the regulation of nutrient homeostasis: firstly, as a physiological meal-initiation signal, and secondly as a component participating in the complex interplay of counter-regulatory hormones released for energy balance. Ghrelin is of great importance in the recurrence of hunger and, as such, contributes to acute ingestive behaviors. Obviously, the view of this high-orectic activity hormone as a common denominator for the feeding drive cannot be conclusive. However, these data underline its feedback modulation of energy intake against negative energy balance. Moreover, leptin - which plays along with ghrelin a pivotal role in the peripheral feedback system controlling energy balance and food intake via modulation of satiety - was not measured [38]. The central mechanisms of ghrelin action were proved by studies in which the dose-dependent effects occurred more profoundly when ghrelin was administered centrally rather than peripherally: the signaling to the central nervous system (CNS) is switched on in times of starvation and when an energy-preserving state is coveted, that is, ghrelin signals the brain when energy must be stored and consumed. As such, the debated hormone is part of a molecular regulatory interface between metabolism and physiological processes regulated by the classical endocrine axes.

Taken as a whole, these results indicate that ghrelin is a signal for energy needs. However, meal initiation may be driven not only by ghrelin but via other synergistic feeding-related mechanisms as well. This hormone's diversified actions in the CNS and wholebody may be induced by external stimuli or, alternatively, by other neuropsychological hunger-associated factors.

The different composition of the snacks was probably responsible for various postprandial plasma ghrelin responses in this healthy population.

The current study presents several important observations regarding the variability of nutritive components of the commercial snacks. This variability was well described by some snacks (B and F), which had a very small excursion of glycemia. In detail, snack B outlined a favorable glycemic profile matching with a neatly suppressed plasma ghrelin concentration in the 3-h postabsorptive status. Paradoxically, this snack could not be detrimental if offered to obese subjects or even diabetic patients.

In conclusion, which macronutrient could potentially influence postprandial ghrelin suppression induced by 6 isoglucidic snack meals was tested. The present findings pointed at the fat content as a major factor triggering ghrelin decline after meal ingestion. In the presence of today's high palatable and abundant food supply in industrialized countries, snack food must be carefully considered according to their variable hormone-stimulating nutrient composition.

\section{Acknowledgements}

$\nabla$

Soremartec Italia S.r.l.; Alba, Italy sponsored the present study.

\section{References}

1 Jahns L, Siega-Riz AM, Popkin BM. The increasing prevalence of snacking among US children from 1977 to 1996. J Pediatr 2001; 138: 493-498

2 Willett W, Manson J, Liu S. Glycemic index, glycemic load, and risk of type 2 diabetes. Am J Clin Nutr 2002; 76: S274-S280

3 Ludwig DS. The glycemic index: physiological mechanisms relating to obesity, diabetes, and cardiovascular disease. JAMA 2002; 287: 2414-2423

4 Ludwig DS, Peterson KE, Gortmaker SL. Relation between consumption of sugar-sweetened drinks and childhood obesity: a prospective, observational analysis. Lancet 2001; 357: 505-508

5 Cali AM, Caprio S. Obesity in children and adolescents. J Clin Endocrinol Metab 2008; 93: S31-S36

6 Ogden CL, Carroll MD, Curtin LR, McDowell MA, Tabak CJ, Flegal KM. Prevalence of overweight and obesity in the United States, 1999-2004. JAMA 2006; 295: 1549-1555

7 Lewis CE, Smith DE, Wallace DD, Williams OD, Bild DE, Jacobs DR Jr. Seven-year trends in body weight and associations with lifestyle and behavioral characteristics in black and white young adults: the CARDIA study. Am J Public Health 1997; 87: 635-642

8 Phillips SM, Bandini LG, Naumova EN, Cyr II, Colclough S, Dietz WH, Must A. Energy-dense snack food intake in adolescence: longitudinal relationship to weight and fatness. Obes Res 2004; 12: 461-472

9 Zizza C, Siega-Riz AM, Popkin BM. Significant increase in young adults' snacking between 1977-1978 and 1994-1996 represents a cause for concern!. Prev Med 2001; 32: 303-310

10 Willett WC, Leibel RL. Dietary fat is not a major determinant of body fat. Am J Med 2002; 113 (Suppl 9B): S47-S59

11 Berkey CS, Rockett HR, Field AE, Gillman MW, Frazier AL, Camargo CA $J r$, Colditz GA. Activity, dietary intake, and weight changes in a longitudinal study of preadolescent and adolescent boys and girls. Pediatrics 2000; 105: E56

12 Francis $L A$, Lee $Y$, Birch $L L$. Parental weight status and girls' television viewing, snacking, and body mass indexes. Obes Res 2003; 11: 143-151

13 Smit HJ, Gaffan EA, Rogers PJ. Methylxanthines are the psycho-pharmacologically active constituents of chocolate. Psychopharmacology (Berl) 2004; 176: 412-419

14 Matsui N, Ito R, Nishimura E, Yoshikawa M, Kato M, Kamei M, Shibata $H$, Matsumoto I, Abe K, Hashizume S. Ingested cocoa can prevent highfat diet-induced obesity by regulating the expression of genes for fatty acid metabolism. Nutrition 2005; 21: 594-601

15 www.iotf.org/

16 Gibson SA. Are high-fat, high-sugar food and diets conducive to obesity? Int J Food Sci Nutr 1996; 47: 405-415

17 Pawlak DB, Kushner JA, Ludwig DS. Effects of dietary glycaemic index on adiposity, glucose homoeostasis, and plasma lipids in animals. Lancet 2004; 364: 778-785

18 Roberts SB. High-glycemic index food, hunger, and obesity: is there a connection? Nutr Rev 2000; 58: 163-169

19 Date Y, Kojima M, Hosoda H, Sawaguchi A, Mondal MS, Suganuma T, Matsukura S, Kangawa K, Nakazato M. Ghrelin, a Novel Growth Hormone-Releasing Acylated Peptide, Is Synthesized in a Distinct Endocrine Cell Type in the Gastrointestinal Tracts of Rats and Humans. Endocrinology 2000; 141: 4255-4261

20 Tschop M, Smiley DL, Heiman ML. Ghrelin induces adiposity in rodents. Nature 2000; 407: 908-913

21 Kojima M, Hosoda H, Date Y, Nakazato M, Matsuo H, Kangawa K. Ghrelin is a growth-hormone-releasing acylated peptide from stomach. Nature 1999; 402: 656-660

22 Shiiya T, Nakazato M, Mizuta M, Date Y, Mondal MS, Tanaka M, Nozoe $S$, Hosoda H, Kangawa K, Matsukura S. Plasma ghrelin levels in lean and obese humans and the effect of glucose on ghrelin secretion. J Clin Endocrinol Metab 2002; 87: 240-244

23 Cummings DE, Purnell JQ, Frayo RS, Schmidova K, Wisse BE, Weigle DS. A preprandial rise in plasma ghrelin levels suggests a role in meal initiation in humans. Diabetes 2001; 50: 1714-1719

24 Ariyasu H, Takaya K, Tagami T, Ogawa Y, Hosoda K, Akamizu T, Suda M, Koh T, Natsui K, Toyooka S, Shirakami G, Usui T, Shimatsu A, Doi K, Hosoda H, Kojima M, Kangawa K, Nakao K. Stomach is a major source of circulating ghrelin, and feeding state determines plasma ghrelinlike immunoreactivity levels in humans. J Clin Endocrinol Metab 2001; 86: 4753-4758

25 Bellone S, Rapa A, Vivenza D, Castellino N, Petri A, Bellone J, Me E, Broglio F, Prodam F, Ghigo F, Bona G. Circulating ghrelin levels as function of gender, pubertal status and adiposity in childhood. J Endocrinol Invest 2002; 25: RC13-RC15

26 Horvath TL, Diano S, Sotonyi P, Heiman M, Tschop M. Minireview: ghrelin and the regulation of energy balance - a hypothalamic perspective. Endocrinology 2001; 142: 4163-4169 
27 Tschöp M, Wawarta R, Riepl RL, Friedrich S, Bidlingmaier M, Landgraf R, Folwaczny C. Post-prandial decrease of circulating human ghrelin levels. J Endocrinol Invest 2001; 24: RC19-RC21

28 Kamegai J, Tamura H, Shimizu T, Ishii S, Sugihara H, Oikawa S. Regulation of the ghrelin gene: growth hormone-releasing hormone upregulates ghrelin mRNA in the pituitary. Endocrinology 2001; 142: 4154-4157

29 Perseghin G, Scifo P, De Cobelli F, Pagliato E, Battezzati A, Arcelloni C, Vanzulli A, Testolin G, Pozza G, Del Maschio A, Luzi L. Intramyocellular triglyceride content is a determinant of in vivo insulin resistance in humans: a $1 \mathrm{H}-13 \mathrm{C}$ nuclear magnetic resonance spectroscopy assessment in offspring of type 2 diabetic parents. Diabetes 1999; 48: $1600-1606$

30 Flint A, Raben A, Blundell JE, Astrup A. Reproducibility, power and validity of visual analogue scales in assessment of appetite sensations in single test meal studies. Int J Obes Relat Metab Disord 2000; 24: 38-48

31 Bland JM, Altman DG. Calculating correlation coefficients with repeated observations: Part 1-Correlation within subjects. BMJ 1995; 310: 446

32 Monteleone P, Bencivenga R, Longobardi N, Serritella C, Maj M. Differential responses of circulating ghrelin to high-fat or high-carbohydrate meal in healthy women. J Clin Endocrinol Metab 2003; 88: 5510-5514
33 Joannic JL, Auboiron S, Raison J, Basdevant A, Bornet F, Guy-Grand B. How the degree of unsaturation of dietary fatty acids influences the glucose and insulin responses to different carbohydrates in mixed meals. Am J Clin Nutr 1997; 65: 1427-1433

34 Pirola L, Johnston AM, Van Obberghen E. Modulation of insulin action. Diabetologia 2004; 47: 170-184

35 Schaller G, Schmidt A, Pleiner J, Woloszczuk W, Wolzt M, Luger A. Plasma ghrelin concentrations are not regulated by glucose or insulin: a double-blind, placebo-controlled crossover clamp study. Diabetes 2003; 52: $16-20$

36 Caixas A, Bashore C, Nash W, Pi-Sunyer F, Laferrere B. Insulin, unlike food intake, does not suppress ghrelin in human subjects. J Clin Endocrinol Metab 2002; 87: 1902

37 Lomenick JP, Melguizo MS, Mitchell SL, Summar ML, Anderson JW. Effects of meals high in carbohydrate, protein, and fat on ghrelin and peptide YY secretion in prepubertal children. J Clin Endocrinol Metab 2009; 94: 4463-4471

38 Clément K, Vaisse C, Lahlou N, Cabrol S, Pelloux V, Cassuto D, Gourmelen M, Dina C, Chambaz J, Lacorte JM, Basdevant A, Bougnères P, Lebouc $Y$, Froguel P, Guy-Grand B. A mutation in the human leptin receptor gene causes obesity and pituitary dysfunction. Nature 1998; 392: 398-401 